\title{
DIEGESE DA DURÉE BERGSONIANA NA FILOSOFIA DA NATUREZA DE R. ASSUNTO
}

Lavínia Pereira

(Doutoranda em Filosofia, FLUL)

\begin{abstract}
"Que raizes se prendem, que ramos crescem Neste entulho pedregoso? Filho do homem, Não consegues dizer nem adivinhar, pois conheces apenas Um montão de imagens quebradas, onde bate o sol, E a árvore morta não dá qualquer abrigo, nem o grilo alívio, Nem a pedra seca qualquer ruido de água. Apenas Há sombra debaixo desta rocha vermelha."
\end{abstract}

T. S. Eliot, A Terra Devastada

\section{A agonia da natureza e o "tempo esquecido": odisseia contempo- rânea numa terra devastada}

É na obra fundamental de Rosario Assunto - Il paesaggio e l'estetica - que encontramos uma reflexão que recoloca a natureza no centro de uma reflexão estética, onde contemplação é simultaneamente prazer estético e fruição de si, formas privilegiadas duma experiência integral, aberta por um sentimento vital. Como ponto de partida para esta reflexão fundamentalmente estética, com implicações valiosas para uma filosofia da natureza, descobrimos nessa obra maior de Assunto uma meditação inaugural acerca da questão da temporalidade. Respirando uma atmosfera claramente bergsoniana, esta preocupação de Assunto será, como nos propomos aqui mostrar, de importância chave para a constituição de uma filosofia da natureza inteiramente renovada.

É no contexto de uma ontologia e teleologia da paisagem e do jardim, inauguradas por Assunto, que procuramos compreender de que for-

Philosophica, 32, Lisboa, 2008, pp. 53-67 
ma a reflexão em torno da temporalidade contribui para uma renovada filosofia da natureza; por meio da consideração da paisagem, e da sua especificidade enquanto meta-espacialidade, imagem extensiva e simultânea de uma temporalidade infinita.

Assumindo que esta especificidade introduz um critério inovador de observação dos modos de constituição da imagem própria de cada espaço determinado, preciosa nomeadamente para a consideração do carácter particular dos espaços urbano e industrial, na relação que em si mesmos estabelecem com uma temporalidade infinita.

O diagnóstico da cidade industrial - a megapolis - enquanto espaço de manipulação, produção e consumo, no interior de uma lógica de aniquilamento, somente se torna possível tendo por base a especificidade da sua relação com a temporalidade. É isso mesmo que confirmamos quando Assunto, na sua obra Il paesaggio e l'estetica, num capítulo intitulado "Il tempo smemorato", pretende pensar a experiência do mundo contemporâneo, como experiência dominada pela organização estrutural e sociológica da megapolis, expoente máximo do triunfo tecnológico e mecânico, organizado em função da produção e do uso das matérias primas como objectos de um processo de contínua transformação.

$\mathrm{Na}$ filosofia bergsoniana Assunto encontra as distinções capazes de elucidar o fenómeno do espaço sem memória no qual a urbe contemporânea constitui. Entre o espaço (geométrico) e o tempo interior (durée), isto é, entre quantidade manipulável e qualidade heterogénea, surgem os termos propriamente assuntianos para a valorização da paisagem, e do jardim, como categorias estéticas capazes de sintetizar e superar os equívocos dualistas que geralmente ocupam o espaço de discussão em torno da concepção de natureza e paisagem, dentro e fora do espaço filosófico, a saber, as noções de objectivo e subjectivo; ética e estética; sensibilidade e razão.

As distinções bergsonianas permitem a Assunto a formulação de um critério de compreensão da meta-espacialidade (como imagem finita de uma temporalidade infinita) renovadora da paisagem, por contraposição com o espaço de manipulação e serialização da indústria, onde a densidade temporal se desvanece dando lugar à efemeridade de um "mesmo" presente, que se repete imperturbável. O "tempo esquecido", tempo urbano não histórico mas industrial, é um tempo rectilíneo e sucessivo onde nada se conserva e tudo se dissipa na forma do uso; eis o domínio da homogeneidade perfeita, onde o ritmo sucessivo da produção substitui a duração própria do aparecer da singularidade - somente permitida pela ocorrência de um tempo qualitativo propriamente dito.

1 R. Assunto, «Il tempo smemorato», in Il paesaggio e l'estetica (1973), Palermo, Edizioni Novecento, 2005, pp. 76-78. 
Não ousando colocar o pensamento de Assunto na dependência das categorias bergsonianas, poderíamos no entanto dizer que a sua reflexão é, por sua vez, retroactivamente esclarecedora da intuição chave do pensamento da durée, na medida em que enfatiza as consequências metafísicas e existenciais do abandono definitivo de uma relação essencial com a dimensão temporal, específica da natureza e da vida, nos seus ritmos próprios.

O abandono da especificidade e complexidade dessa relação implica - como Bergson compreendera - a falência de uma ideia de natureza com valor criativo e inclusivo, onde a própria duração humana, histórica e individual, está enraizada. "Senza la natura moriremo!" - é a advertência de Assunto diante do esgotamento técnico e civilizacional, pessoalmente presenciado ${ }^{2}$.

O desígnio da investigação de Bergson em torno do tempo, que tem início no Ensaio sobre os dados imediatos da consciência e se prolonga na Evolução Criadora, através da questão vital, surge aqui de forma clarividente. A analítica da durée não tratava de uma oposição simples entre a interioridade qualitativa da consciência e a exterioridade quantitativa do espaço: na verdade, a distinção operada entre espaço e tempo traduzia um movimento bastante mais vasto e filosoficamente significativo. A distinção entre o modelo da espacialidade geométrica e o modelo da temporalidade como fenómeno absoluto, permite questionar os moldes de um "pensamento operatório" como "pensamento de sobrevoo, pensamento do objecto em geral" e assim fazer o diagnóstico dos moldes de compreensão da natureza, de acordo com um esquematismo operatório da razão, que faz daquela um suporte "naturalista" para uma manipulação técnico-industrial ${ }^{3}$ apurada. Os limites do modelo mecanicista, perfeitamente compreendidos pelo filósofo francês, revelam a inevitabilidade do caminho para uma "terra devastada" 4 de onde os valores da vida e da natureza como renovação estão definitivamente ausentes, caminho que traduz a vivência contemporânea de um mundo fragmentado, expondo a experiência humana actual ao esvaziamento e à deterioração.

2 R. Assunto, Il paesaggio e l'estetica (1994), Palermo, Edizioni Novecento, 2005, p. 175.

3 Cf.: "O pensamento "operatório" torna-se uma espécie de artificialismo absoluto, como vemos na ideologia cibernética, onde as criações humanas derivam de um processo natural de informação, mas ele próprio concebido a partir do modelo das máquinas humanas [...] o homem torna-se verdadeiramente o manipulandum que julga ser", in M. Merleau-Ponty, L'oeil et l'esprit, Paris, Gallimard, 1964, pp. 11-12.

4 T.S. Eliot, The Wasteland (1922). A Terra Devastada, trad. portuguesa G. Cunha, Lisboa, Relógio d'Água Editores, 1999. 


\section{Do "tempo esquecido" ao "tempo reencontrado": a temporaneidade exclusiva da megapolis e a natureza como experiência de renovação}

À semelhança do que acontecia com Bergson, por meio de uma crítica ao cientismo e mecanicismo dominantes, quer no domínio científico quer em ambiente filosófico, a experiência do mundo contemporâneo vem a constituir no interior do pensamento de Assunto um diagnóstico pessimista, fundamentalmente elaborado a partir da experiência da especificidade do universo técnico-industrial no modo da sua relação com a temporalidade.

A analítica do tempo levada a cabo por Bergson, que tomamos como referência para a esta reflexão, deixava bem claras as consequências do convencionalismo científico ao nível da compreensão filosófica da concepção de tempo, mostrando a forma como a filosofia evitava a vertigem do tempo e do movimento absolutos da dinâmica vital, em termos gerais, e dos dados imediatos da consciência, em particular. O esquecimento ou a ocultação da dimensão efectiva, e simultaneamente virtual, da temporalidade absoluta, pareciam integrar o próprio modus operandis científico, por meio da ascensão ímpar de uma razão do cálculo - uma razão mecânica - com consequências filosóficas e existenciais profundas, que passavam nomeadamente pela consideração de um universo estritamente quantificável e definitivamente previsível.

Precisamente do mesmo modo que em Bergson, a advertência para uma perda irrecuperável, observável já na experiência humana contemporânea de uma deriva - onde arbitrariedade não é sinónimo de novidade funda-se também ela numa analítica do tempo, desta feita, partindo de uma avaliação da relação dos modos de vida contemporâneos com a própria temporalidade. A experiência inteiramente assumida de um esgotamento das formas na pós-modernidade revela um fundo quer de esquecimento, quer de ocultação da temporalidade fundadora. $\mathrm{O}$ que reconhecemos de forma inédita em Assunto é a sua capacidade de compreender que essa ocultação de uma relação essencial com o tempo, cujas consequências observamos na vida contemporânea, tem origem precisamente no facto da ausência da natureza do domínio da nossa quotidianidade.

A razão de uma decadência acelerada, que convive simultaneamente com um progresso inaudito, reside na impossibilidade de encontro com o espaço que se revela imagem original de um processo de renovação e imprevisibilidade, próprios de uma temporalidade infinita. O desenho da quotidianidade contemporânea faz-se antes por referência a um tempo sem memória nem espera - il tempo smemorato - regulando-se essencialmente pelo ritmo do trabalho de produção e do consumo, afastando o homem de uma relação essencial com a temporalidade infinita. 
Perante a deterioração das formas naturais e a sua ausência definitiva da megapolis, em virtude do crescimento acelerado e da predominância das zonas industriais "extra-urbanas", que invadem as áreas circundantes da cidade propriamente dita, altera-se definitivamente a compreensão histórica da urbe por referência à coexistência espacial e imagética dos tempos históricos sucessivos. A cidade pós-histórica ou industrial é então a imagem que configura e enquadra a experiência humana contemporânea da finitude.

"Finitude, o espaço da Megapolis, que é negação do infinito, resoluta e peremptoriamente, pelo qual a cidade pós-histórica, isto é, a cidade tecnológica e industrial, se contrapõe à paisagem, que é excluída e à qual vira as costas, colocando entre o seu limite extremo e toda a possibilidade de paisagem, o território extra-urbano; o qual, a respeito da paisagem é algo mais que negação, é contradição absoluta"5.

A megapolis é precisamente esse espaço homogéneo de ocultação, sem retorno e sem referência, é deriva indefinida e finitude elevada, porquanto dissimula a temporalidade fundadora, na medida em que todos os seus tempos são escandidos pelo ritmo serial e homogéneo da produção e da tecnologia. A temporaneidade absoluta da megapolis é esse mesmo envelhecimento sem memória, futuro sem novidade, sem qualquer vestígio da "imortalidade da natureza".

Espaço sem referência nem enraizamento, que da terra faz tábua rasa, é pura e simplesmente urbano, não reenvia a nenhum domínio outro, constitui-se pois como espaço de mesmidade e permanência, sem recolhimento nem descanso. A megapolis constituiria a imagem típica de um tempo contemporâneo perpassado pelo murmúrio ininterrupto de um tempo neutro, um il y a, a experiência de um lugar onde a existência é apenas impessoal e irrevogável, sem descanso nem alteridade 6 . Uma experiência fragmentária, enredada em si, sem indício de apelo nem exterioridade, como as palavras de T.S. Eliot, reproduzidas em epígrafe, tão bem indiciavam.

Somente a abertura e exterioridade da paisagem, no seu perfil estético, permitem compreender a contradição e exclusão do ritmo urbano relativamente à temporalidade infinita, enquanto ritmo da integração e do retorno, do mesmo e da novidade não contraditórios, sempre revelados no aparecer da eterna primavera.

${ }^{5}$ R. Assunto, Il paesaggio e l'estetica, p. 90.

6 Fazemos aqui uma referência a E. Levinas, a partir da sua obra Le temps et l'autre (1948), Paris, PUF, 2004. Pela força da categoria filosófica de "il y a", mas também pela concepção de alteridade que convoca no âmbito da sua ética que nos parece pertinente no contexto desta nossa reflexão, pela urgência em compreender a paisagem como espaço de alteridade e heteronomia. 


\section{A descoberta de uma temporalidade fundadora: da "atitude estéti- ca” como experiência de renovação}

A uma razão ecológica ou biológica - espécie de antídoto da ciência e da tecnologia para nos salvar do seu próprio veneno - Assunto contrapõe uma razão estética que exporá, no seu poder criativo, a dimensão da temporalidade duplamente integradora do homem e da natureza, e isto porque, "ao contrário do conceito físico, objectivo e genérico, a paisagem é integrada no âmbito dos fenómenos perceptivos [...]. [Pela contemplação estética] o elemento referencial ao observador resguarda a especificidade da natureza-paisagem distinguindo-a das noções científicas"7.

Ressalvar a especificidade da natureza-paisagem, isto é, a sua alteridade, por meio de uma integridade estética, enquanto lugar de contemplação e de vida - no qual o homem está integrado - abre uma distância filosoficamente significativa relativamente àquele procedimento da pensée opératoire, para a qual o lugar natural é idêntico a um objecto $\mathrm{x}$, absorvido no enunciado geral, da geofísica, da geografia, ou do urbanismo paisagístico. $\mathrm{O}$ modus operandis desse pensamento operatório retira à natureza o seu ser espelho da temporalidade qualitativa, enquanto virtualidade, processo onde novidade e criação traduzem a dimensão efectiva da "variável" tempo.

Absorvida no ritmo da manipulação e do consumo, que caracterizam o tempo da indústria e da megapolis, o desaparecimento da paisagem, como configuração da natureza integral, e como referência última do próprio espaço urbano, anteriormente representado na meta-espacialidade da cidade histórica ${ }^{8}$, leva consigo a experiência do tempo como heterogeneidade qualitativa, sinónimo de vida e renovação.

Transformada em "meio" ou "território" a paisagem passa, pelo contrário, a integrar uma lógica de domínio", perdendo definitivamente o seu

\footnotetext{
${ }^{7}$ A. Serrão, «Filosofia e Paisagem. Aproximações a uma Categoria Estética», Philosophica, 23 (2004), p. 93.

${ }^{8} \mathrm{Cf}$. "A história que nasce da natureza e a ela regressa; a cidade que nasce na paisagem e se reconverte em paisagem: naquela paisagem que a gera e a acolhe; que é anterior e posterior à cidade, como a natureza é anterior e posterior à história: mortalidade da cidade e da história, imortalidade da natureza. [...] A qual inclui em si a imagem espacial (uma espacialidade que é meta-espacialidade) da temporalidade da história: aquela temporalidade histórica na qual [...] a inerência recíproca do presente, do passado e do futuro não conhece repetição e retorno, mas somente novidade e memória.”, in R. Assunto, Il paesaggio et l'estetica, pp. 104-105.

9 Cf.: "Territórios a que se chamava "províncias" [...] também eles delimitados arbitrariamente sobre a base dos princípios racionalistas do século das Luzes que, de um ponto de vista filosófico, privilegiavam o "espaço" em relação ao "tempo", a "geografia" em relação à "história” e renegavam a memória.", in R. Assunto, «Pay-
} 
carácter essencial. Eis os moldes no interior dos quais ocorria a passagem a uma temporaneidade urbana irrevogável, feita imagem no espaço da megapolis, como lugar de ocultação da relação essencial à temporalidade infinita: "O tempo rectilíneo, o tempo sem memória e sem espera, é o tempo da tecnologia e da sua filha a indústria. É a sucessão que nada conserva, mas tudo destrói, ao contrário da durée bergsoniana. Sucessão pura, não só sem retorno, mas também sem recordação; sucessão na qual nada se repete nada se renova. [...] Onde o futuro é programado [...] é resultado de um cálculo. Futuro sem espera: porque a sua novidade será uma falsa novidade, a novidade perfeitamente prevista, em relação à qual nada é temido, mas também nada é esperado"10.

Realizada por Bergson, na sua obra de 1889, e aqui referida por Assunto, a analítica da duração psicológica, por contraposição com a convenção da espacialidade geométrica, dizia essa mesma absorção dos movimentos e dos tempos reais na igualdade quantitativa de um tempo espacial, cuja homogeneidade absorvia necessariamente a singularidade do acontecimento. A analítica do espaço, categoria social e científica, permitia-nos compreender o modo como a singularidade qualitativa de um acontecimento era quantitativamente integrada numa medida comum, por referência a um suporte homogéneo imaginário - o espaço geométrico.

Esta distinção não se fundava todavia numa oposição simples entre interior e exterior mas, pelo contrário, revelava dois modos da relação entre cada um desses domínios e a temporalidade absoluta e integradora da durée; mais tarde traduzida e ampliada através da ideia de um élan vital.

Descobrindo que o espaço geometricamente concebido e justaposto à experiência real do espaço, pela convenção científica e social, é um artificialismo do qual foi abolida toda a possibilidade de experiência qualitativa. Bergson mostra-nos no seu Ensaio sobre os dados imediatos da consciência ${ }^{11}$ que o problema da convenção, fundada sobre o molde das medidas comuns não é a falsidade, mas antes o facto de absorver num sistema homogéneo toda e qualquer experiência, introduzindo as singularidades e os acontecimentos únicos no domínio quantitativo do pensamento operatório.

Anulando a possibilidade de uma compreensão da singularidade anula-se simultaneamente a possibilidade de consideração da alteridade,

sage, lieu et territoire» (1981), Le retour au jardin. Essais pour une philosophie de la nature, 1976-1987, textes réunies et traduits de l'italien par H. Brunon, Paris, Les Éditions de l'Imprimeur, 2003, pp. 43-44.

10 R. Assunto, Il paesaggio e l'estetica (1994), Palermo, Edizionni Novecento, 2005, p. 76.

11 H. Bergson, Essai sur les données immédiates de la conscience (1889), Euvres, Paris, PUF, 1959. 
pela referência a uma medida comum, introduzida pela ciência ou pela convenção social, segundo os mesmo critérios de uma razão intelectualista: a verdadeira diferença é anulada e o outro vem a ser dissolvido no domínio do mesmo.

De acordo com o mesmo tipo de procedimento, a constituição da paisagem ou da natureza em objecto de estudo para a ciência, seja ela a biologia, a geofísica ou o urbanismo, anula a alteridade que a constitui, agrupando-a num ou noutro conjunto de objectos gerais, porquanto sem referência a uma realidade heterogénea a singularidade da paisagem natural é automaticamente apagada.

A reflexão de Assunto mostra-nos precisamente que a experiência estética é, por excelência, aquela que nos permite apreender a especificidade natural da paisagem, pela sua dimensão reveladora da temporalidade infinita. É isso mesmo que a constitui como experiência de renovação, porquanto permite e revela uma relação essencial com a heterogeneidade própria de uma temporalidade criativa.

Não podemos portanto concordar com a análise de M. Lima, segundo a qual Assunto "leva ao extremo a dicotomia entre paisagem e espaço urbano, assumindo que, onde um começa o outro acaba"12. Acreditamos não se tratar de uma dicotomia simples entre dois espaços de tipos diferentes, mas da relação que com eles estabelecemos, do modo como ocultam ou revelam a relação essencial entre os acontecimentos e a heterogeneidade que os constitui, enquanto fenómenos finitos de uma temporalidade infinita. Espaços temporâneos que revelam ou ocultam a dimensão fundadora de uma temporalidade infinita e que, desta forma, se constituem ou não lugares de meta-espacialidade.

Quando, neste contexto, referimos a especificidade da temporalidade natural, cuja imagem se constitui na meta-espacialidade da paisagem, não podemos contrapor-lhe simplesmente a categoria do espaço urbano, como imagem de uma temporaneidade finita, que se reflecte no ser histórico da cidade. A temporalidade infinita não se refere a um tempo equiparável a outros tempos, mas antes à dimensão fundadora do tempo natural. Assim, quando pensamos na paisagem, como imagem espacial da temporalidade natural, não é no tempo das paisagens que pensamos, mas na temporalidade natural (reveladora da temporalidade infinita) como fundadora das temporalidades, como contendo em si a possibilidade de se revelar diferentemente nos modos da temporaneidade finita, numa imagem espacial.

É isto mesmo que fica claro na secção intitulada "Il tempo della storia e il tempo della natura"13, na qual R. Assunto mostra que a imagem

12 M. Lima, «Estéticas da paisagem e arquitectura paisagista», Philosophica, 29 (2007), p. 95.

13 R. Assunto, Il paesaggio e l'estetica (1994), Palermo, Edizioni Novecento, 2005, p. 94-113. 
da vila histórica - o tempo de que a cidade é imagem espacial - não se opõe à paisagem natural na temporalidade que lhe é própria, mas antes aponta para ela, não existe sem ela: "A temporalidade da natureza mostra-se na temporaneidade: não como contradição, mas como justificação da temporaneidade, do próprio passar do tempo, enquanto um movimento que regressa a si mesmo: na verdade, segundo a definição platónica, uma imagem móvel da eternidade. E esse seu configurar-se imagem móvel da eternidade coloca o tempo da natureza nos antípodas daquele tempo rectilíneo da técnica (e consequentemente da indústria)"14. Não se trata portanto de uma contradição ou de uma dicotomia simples, mas de uma diferença de natureza - no sentido bergsoniano do termo - entre o tempo natural e o tempo da técnica não encontramos uma diferença de grau mas uma diferença qualitativa, a mesma diferença que encontramos entre o aberto e o fechado, isto é, entre a imprevisibilidade criativa e a repetição regulada das formas ${ }^{15}$.

Torna-se portanto impossível compreender a especificidade fundadora da temporalidade infinita em Assunto sem nos reportarmos ao conteúdo significante da durée bergsoniana, não estritamente psicológica, mas sobretudo na sua relação com a ideia de vida. Aquele finitizar-se no espaço, o devir temporâneo da pura temporalidade torna-se inteiramente necessário.

Somente na consideração da pura temporalidade podemos encontrar o fundamento ontológico da experiência da espacialidade finita ${ }^{16}$, e dessa forma compreendê-la como lugar de renovação enquanto imagem de uma temporalidade inclusiva. As palavras de Assunto ilustram-no de forma clarividente: "Devemos tomar consciência que este finitizar-se no espaço, e devir temporâneo, é necessário à temporalidade pura, não menos do que a nós nos é necessário pensar a temporalidade na sua pureza para justificar a temporalidade finita que nós próprios somos [...] tomando consciência do valor de cada presença enquanto manifesta temporaneamente a temporalidade absoluta" 17 .

É no espaço da paisagem que encontramos o testemunho desse processo: um constituir-se do espaço como representação extensiva e simultânea do tempo ${ }^{18}$. O espaço da paisagem é a abertura pela qual passa o fio da temporalidade infinita, unidade heterogénea de passado, presente e futuro.

14 R. Assunto, Il paesaggio e l'estetica, p. 106, (sublinhado nosso).

15 Cf. H. Bergson, Les deux sources de la morale et de la religion (1932), Euvres, Paris, PUF, 1959.

16 Obviamente já não estamos a falar da espacialidade geometricamente determinada, mas da vivência real de uma espacialidade inteira.

17 R. Assunto, Il paesaggio e l'estetica (1994), Palermo, Editionne Novecento, 2005, p. 108.

18 Cf. R. Assunto, Il paesaggio e l'estetica, p. 71. 


\section{Diegese estética das categorias de heterogeneidade e interpenetra- ção da durée bergsoniana}

Próprio da paisagem, como imagem da temporalidade infinita da natureza, é a presença de vida, actual ou virtual. O "sentimento vital" como sentimento que acompanha a experiência estética da paisagem, traduz esse movimento de reconhecimento do homem na paisagem, pela sua dinâmica criativa e renovadora, explícita no tempo próprio das formas vivas nela presentes. $\mathrm{O}$ espaço da paisagem mostra essa mesma:

“anterioridade da natureza em relação à vida, [...] tal é já significativo para progredirmos na investigação que nos propomos aprofundar, da nossa análise acerca da paisagem, enquanto espaço que representa o tempo da natureza que é o tempo a partir do qual, no qual e do qual a vida é; tempo que coincide com o próprio ser fundante da vida, enquanto o tempo, cuja imagem é a instalação industrial [...] é o tempo no qual a vida se nega e é abolida, um tempo serializado e mecanizado" 19 .

Este reconhecimento funda-se na compreensão da meta-espacialidade da paisagem como imagem da temporalidade infinita que no seu ritmo de doação e renovação das formas vivas é sinónimo de heterogeneidade e abertura ${ }^{20}$. Cuja significação não dispensa, na nossa perspectiva, a referência a uma temporalidade fundante sem a qual é impossível compreender o sentido específico que Assunto atribui à natureza, como temporalidade circular e renovação das formas vivas, mas igualmente de referência à imobilidade e permanência das formas naturais (nomeadamente na presença inabalável do universo mineral).

Se tentamos compreender o espaço da paisagem como um espaço contíguo a outros espaços ${ }^{21}$ arriscamo-nos a perder de vista esta sua especificidade, enquanto representação espacial que revela diferentemente os modos de uma relação essencial à temporalidade infinita, através da multiplicidade das formas que a habitam.

Quando colocamos o espaço natural numa relação gradativa relativamente aos restantes espaços - urbano e industrial - ocultamos a sua dimensão fundante. Como tal, torna-se imprescindível esclarecer os mol-

19 R. Assunto, Il paesaggio e l'estetica, p. 117.

20 Para esta nossa interpretação é igualmente fundamental a compreensão da ideia de vida na filosofia bergsoniana, fundamentalmente a partir da sua obra de 1907, L'Evolution Créatrice.

${ }^{21} \mathrm{Cf}$. M. Lima, «Este autor [Assunto] leva ao extremo a dicotomia entre paisagem e espaço urbano, assumindo que, onde um começa o outro acaba.», in «Estéticas da paisagem e arquitectura paisagista», Philosophica, 29 (2007), p. 95. 
des no interior dos quais a paisagem é essa "finitude aberta", imagem da temporalidade inclusiva e heterogénea da natureza; compreendendo que a diferença entre o espaço urbano e o espaço da paisagem não significa somente uma diferença entre temporaneidade e temporalidade, mas antes uma diferença de natureza na relação que os espaços temporâneos estabelecem com a temporalidade - sejam eles o espaço urbano ou paisagístico. Não se trata de uma oposição simples entre espaços diferentemente configurados, mas de uma diferença fundamental que os constitui, na medida em que o seu modo de ser revela ou anula uma relação essencial com a temporalidade infinita.

A perspectiva que encontramos em A. Lima, traduzindo a perspectiva da arquitectura paisagista: "esta posição [de Assunto] não é real e não é por isso adoptada: a paisagem é rural, urbana, industrial ou turística; ela atravessa as várias realidades e garante que o tempo seja um só nessas mesmas realidades" 22 , mostra-nos como o essencial da ideia de paisagem, enquanto revelação de um tempo inclusivo e heterogéneo, é precipitadamente abolido.

Compreender a especificidade que aqui está em causa significa compreender a impossibilidade de uma passagem do tempo da urbe ao tempo da paisagem através de uma intensificação dos valores naturais aí presentes; entre o tempo da natureza e o tempo da indústria existe, como dizíamos anteriormente, a mesma diferença que entre o aberto e o fechado. $\mathrm{O}$ problema da megapolis e do espaço industrial, como modos de uma espacialidade absorvente e aniquiladora, residia precisamente no facto de ocultarem, e inviabilizarem, a relação essencial entre o viver temporâneo e finito de um espaço e o seu ser representação de uma temporalidade infinita e integradora ou aberta.

Por outro lado, preservar a alteridade da natureza-paisagem significa necessariamente identificá-la como uma realidade na qual o homem está enraízado, e não um objecto em face do qual ele se coloca. Isto é, compreendê-la como espaço de doação e integração da vida, que se mostra na própria contemplação estética. Lugar de uma experiência vital fundadora: encontro e reconhecimento da temporalidade própria do viver humano na dinâmica vital da natureza-paisagem, pela diversidade das suas formas. Espaço vivo e habitado de encontro entre temporaneidades, que a seu modo revelam diferentemente o finitizar-se, de uma temporalidade infinita, numa diversidade viva. A contemplação da natureza, na experiência estética da paisagem, revela ainda esta diferença essencial relativamente ao tempo da indústria:

"Quando falamos de paisagem, entendemos um ambiente vivo, por

22 M. Lima, «Estéticas da paisagem e arquitectura paisagista», p. 95, itálico nosso. 
vivo entendo múltiplo e diverso, impassível de ser seriado, como não são seriáveis os produtos da natureza [...] Todos os produtos da natureza enquanto seres vivos são diversos, enquanto todos os produtos da indústria são idênticos - [sendo que] a identidade é quantidade absoluta, a diversidade é absoluta qualidade" ${ }^{23}$.

O que faz a diversidade e unicidade dos seres vivos, enquanto impassíveis de serialização? Precisamente o modo como neles ocorre e se revela a dimensão fundadora da temporalidade; onde passado, presente e futuro estabelecem uma relação de heterogeneidade e interpenetração ausente dos produtos (idênticos entre si) da indústria. Os seres naturais revelam diferentemente, enquanto realidades qualitativas e impassíveis de serialização, o finitizar-se, o devir imagem extensiva da temporalidade infinita.

O que é próprio da experiência estética da paisagem-natureza é o modo como esta revela a especificidade das relações entre passado, presente e futuro, na presença actual, isto é, nos elementos que a compõem, de modos inteiramente diversos, e sempre complementares. A coexistência dos tempos - passado, presente e futuro - fundamental para a compreensão da diversidade viva da natureza-paisagem deve, no entanto, ser cuidadosamente especificada: primeiramente, importa compreender a que se refere essa coexistência dos tempos (do tempo); de seguida, esclarecer o modo como ela ocorre diferentemente nos três reinos da natureza.

Cada um dos domínios do universo natural - mineral, vegetal e animal - na medida em que revela uma relação própria com a temporalidade infinita, constitui um modo próprio da relação entre os três tempos do Tempo, obrigando-nos a pensar a temporalidade como algo não linear nem cronológico - à maneira bergsoniana de uma durée heterogénea onde os tempos se interpenetram - onde passado é memória, e futuro é espera ou projecto.

\subsection{Temporalidade natural e reversibilidade}

A seu modo cada um dos domínios da natureza explicita diferentemente aquilo que era dito por Bergson acerca da dimensão absoluta da durée, de acordo com a qual a interpenetração constitutiva dos três tempos - passado, presente e futuro - constituía uma diversidade "infinita" segundo os moldes da relação que estabeleciam entre si, de forma que na durée cada um dos momentos do tempo reflectia, a seu modo, os outros "momentos" 24 do tempo. Este sistema de interpenetração traduzia o modo

23 R. Assunto, Il paesaggio e l'estetica, p. 115.

$24 \mathrm{Na}$ obra Essai sur les données immédiates de la conscience (1889), Bergson chega mesmo a pôr em causa a possibilidade de lhes chamar momentos do tempo, mais 
de acordo com o qual ocorria a contracção dos tempos no tempo presente, complexidade que se mostrava na famosa figura do cone, utilizada em Matéria e Memória ${ }^{25}$, de acordo com as infinitas possibilidades de combinação que eram estabelecidas entre os dois limites virtuais do cone, da memória pura e inconsciente à percepção pura e inteiramente presente. De acordo com Assunto, estas formas de interpenetração estão presentes nos três reinos do universo natural, constituem a sua meta-espacialidade, enquanto imagens de uma temporalidade infinita.

A rocha e a pedra - reino mineral - na sua presença infinita e imóvel revelam ser imagens de uma identidade firme e dominadora das três formas do tempo. O terceiro elemento da paisagem mineral - a água - é pelo contrário símbolo de uma identidade móvel, de uma mobilidade contínua, onde mesmo e novo, passado e futuro, coincidem a cada momento ${ }^{26}$.

Identidade e diferença, a rocha e a água, elementos minerais, são dois modos inteiramente diversos de ser na paisagem: o primeiro como identidade do mesmo e de impassibilidade; o segundo, como movimento absoluto, de sucessiva apreensão do passado e do presente pelo futuro sempre já anunciado. O elemento mineral da paisagem mostra os sinais primários que constituem a própria temporalidade entendida como durée, e que constituem igualmente o paradoxo que a caracteriza, como movimento de integração do mesmo e de diferenciação: "coextensividade específica de presente, passado e futuro, que estão uns nos outros por inteiro, e todos os três em cada um" 27.

Repetição do mesmo que é já outro, e diferenciação do mesmo consigo, porquanto o futuro não pode ser efeito mecânico de uma configuração prévia do passado: este segundo aspecto da dinâmica de virtualidade própria da durée, este paradoxo que constitui o jogo permanente entre memória e reversibilidade, encontramo-lo igualmente na paisagem assuntiana, na medida em que é identidade imemorial e antecipação do imprevisível. Falamos da presença do segundo elemento constitutivo da paisagem, a vegetação, que de acordo com o seu ritmo próprio cria um ciclo de identidade e diferença, de novidade do mesmo e mesmidade do novo,

tarde, em Matière et Mémoire (1896), a figura do cone exprime com maior eficácia o sentido forte da durée como interpenetração real dos tempos do tempo.

25 H. Bergson, Matière et Mémoire, Euvres, Paris, PUF, 1959, Chapitre III, pp. 276$-314$.

26 Cf.: "Se a pedra, o mineral em geral, é presença de todo o passado e de todo o futuro, a água, elemento líquido, é passado e futuro juntos em todo o presente [...] o elemento aquoso é imagem da temporalidade própria na misteriosa unidade de passado e futuro [...] pelo qual o presente é aquilo que passado e futuro têm em comum [...] a água é tal que nela o mesmo é sempre novo, o sempre novo é o mesmo.", in R. Assunto, Il paesaggio e l'estetica, pp. 121-122.

27 R. Assunto, Il paesaggio e l'estetica, p. 132. 
onde reconhecemos de forma notável a "circularidade das estações, sobre a qual se funda a temporalidade do reino vegetal" 28 .

Esta dinâmica cíclica está hoje praticamente ausente da experiência urbana do homem contemporâneo, onde se anula a circularidade do tempo, marca da infinitude renovadora da natureza, para se concentrar na experiência contraditória da finitude estrita e irrevogável:

"As estações, como sinal do tempo que retorna, desmentem toda a irreversibilidade, são testemunhas disso, na paisagem - e importa notar que a vegetação é temporalidade que retorna, enquanto a produção mecânica se baseia sobre a temporalidade irreversível [...] Enquanto se funda na irreversibilidade, a indústria tem por fim a absoluta paragem qualitativa do tempo, à qual corresponde um nivelamento qualitativo do espaço $[\ldots]]^{\prime 29}$.

De forma semelhante, mas de acordo com um reconhecimento mais imediato e mais intensamente significante, podemos falar da presença do animal na paisagem como presença mesma da vida, "uma imagem da vida como tal, na qual toda a vida se reconhece como vivente" 30 . Infinitude que se mostra, igualmente ao estilo bergsoniano, dinâmica de criação e configuração da finitude da criatura, na cristalização das formas vivas e autónomas, elas mesmas presentificação de uma finitude aberta. Como lugares da imprevisibilidade e da inexauribilidade da temporalidade infinita da natureza-paisagem, isto é, da sua efectiva alteridade.

Sem podermos alongar-nos numa explicitação detalhada da diversidade dos modos de doação da temporalidade infinita, na imagem espacial dos elementos naturais - segundo os critérios da durée bergsoniana queremos no entanto realçar e dimensão da proposta de Assunto, que passa por uma renovada filosofia da natureza, e estabelece a dimensão fundadora da temporalidade infinita, desocultando o vínculo que as une.

Reflexão de consequências altamente significativas, aqui delineadas, para a compreensão da paisagem-natureza, como lugar de contemplação estética, que restitui o finito à sua infinitude primeira, presentificando os movimentos de reversibilidade e renovação definitivamente ausentes do tempo tecnológico e industrial. Neste domínio, a advertência de Assunto não se limita ao diagnóstico de uma ausência irreparável, mas revela igualmente a origem e o destino que delimitam os propósitos de uma razão mecanicista e tecnológica, apontando para a necessidade de integração da paisagem na cidade, valor para o qual esta deve apontar, como para o seu fundamento.

28 R. Assunto, Il paesaggio e l'estetica, p. 136.

29 R. Assunto, Il paessagio e l'estetica, p. 138.

30 R. Assunto, Il paesaggio e l'estetica, p. 140. 


\section{RESUMO}

$\mathrm{O}$ artigo procura esclarecer mutuamente a filosofia da natureza de Rosario Assunto, em particular a partir da sua obra magna - Il paesaggio e l'estetica -, e a natureza da durée bergsoniana - a partir das obras Essai sur les donnés immédiats de la consciente e Matière et Mémoire. Mostra-se o carácter fundamental de um pensamento da temporalidade para a constituição de uma renovada filosofia da natureza. Os critérios estabelecidos pela durée bergsoniana permitem a Assunto a elaboração dos dois conceitos-chave - temporalidade e temporaneidade amplamente operativos para a compreensão da experiência estética da paisagem enquanto imagem espacial de uma temporalidade infinita ou meta-espacialidade, distinguindo-a da experiência temporânea da megapolis. Finalmente, pretende-se mostrar o carácter fundador da temporalidade da natureza relativamente ao tempo da cidade histórica, que a grande metrópole contemporânea tende a ocultar.

\section{RÉSUMÉ}

L'article se propose d'élucider à la fois la philosophie de la nature de Rosario Assunto, notamment à partir de l'œuvre - Il paesaggio e l'estetica -, et la nature de la durée bergsonienne - à partir des œuvres Essai sur les données immédiates de la conscience et Matière et Mémoire. On remarque le caractère fondamental d'une pensée de la temporalité dans la constitution d'une philosophie de la nature renouvellée. Les critères établis par la durée bergsonienne permettent à Assunto la création des deux concepts-clé - temporalité et temporaneité - indispensables pour comprendre l'expérience esthétique du paysage en tant qu'image spatiale d'une temporalité infinie, ou meta-spacialité, en l'opposant à l'expérience temporaine de la megapolis. On prétend, en plus, montrer le caractère fondateur de la temporalité de la nature par rapport au temps de la ville historique, progressivement dérobé dans la métropole contemporaine. 